\title{
Türkiye'de Zekatın Kurumsallaşmasına Sosyo-Kültürel Bir Yaklaşım
}

\section{Muhammed Beşir Çalışkan *}

Received: 01.11.2019

DOI: $10.25272 /$ ijisef.641305
Accepted: 04.01.2020

Type: Research Article

\section{$\ddot{O} z$}

Zekatın organizasyon yapısına kavuşturulması meselesi, günümüz Müslümanları adına önemli bir yere sahiptir. Bu doğrultuda değişik coğrafyalarda önemli çalışmalar yapılmış, müesseseleşme yaygınlaşmıştır. Bu çalışmaların arkasında sadece dini nedenler dayanak olarak gösterilmemiş, meselenin diğer boyutları da ortaya konmaya çalışılmıştır. Çalışmada bu nedenler dört ana başlık altında, ekonomik, siyasi, sosyal ve dini açıdan değerlendirilmiştir. Ülkemiz özelinde de kurulması muhtemel böyle bir yapının, ne gibi zorluklarla karşılaşacağı toplumda var olan armağan ilişkileri ve bağlamsal ahlak üzerinden gösterilmiştir.

Anahtar Kelimeler: Zekat, Kurumsallaşma, Armağan Kültürü, Bağlamsal Ahlak

Jel Kodlar1: B59, E02, E71

\section{A Socio-Cultural Approach to Institutionalization of Zakat in Turkey}

\begin{abstract}
The issue of establishing zakat institute is crucial for contemporary Muslim world. Several studies have been carried out in different geographies and institutionalization has become widespread. Beyond these studies, not only religious reasons were shown as a basis, but other aspects of the issue were tried to be considered. The reasons are evaluated under four main categories: economic, political, social and religious. The difficulties that may be confronted in Turkey, have been demonstrated through the potlach and contextual morality in the society.
\end{abstract}

Keywords: Zakat, Institutionalization, Potlach, Contextual Morality

Jel Codes: B59, E02, E71

\footnotetext{
* Arş. Gör., Sakarya Üniversitesi, İslam Ekonomisi ve Finansı Uygulama ve Araştırma Merkezi, muhammedcaliskan@sakarya.edu.tr, ORCID: https://orcid.org/0000-0002-3990-9794
} 


\section{Giriş}

Zekat, cari ekonomik düzene alternatif bir model arayışında olan Müslümanlar için sosyal adaleti temin noktasında ilk akla gelen çözümlerden biridir. Sadece zekat ibadetinin tam bir şekilde yerine getirilmesi ile bu amacın gerçekleşeceğine yönelik inanç insanlar arasında oldukça yaygındır. Türkiye özelinde de bu doğrultuda çalışmalar yapılmıştır (Gümüş, Yardımcıoğlu ve Altıntaş, 2019). Dolayısıyla araştırmacıların, politika yapıcılarının ve sivil toplum kuruluşlarının bu alana ciddi bir ilgisi mevcuttur. Özellikle İslam İktisadı ile ilgili çalışmaları olan kişilerin zekat konusunu göz ardı etmeleri mümkün değildir. Bu popüler konunun en önemli gündemlerinde biri de zekatın devlet eliyle kurumsallaştırılmasıdır.

Zekatın kurumsallaşmasını tartışmadan önce kurumsallaşmanın kendisini irdelememiz daha doğru olacaktır. Türkiye'de bir kurum ihdas edildiğinde, kurumun kurulmasına neden olan problemin de ortadan kaldırıldığına yönelik bir algı söz konusudur (Önderman, 2007). Bunu delillendirmek için klasik bir örnek olarak Tanzimat döneminden günümüze bürokrasinin toplumu dönüştürmek için takındığı tepeden inmeci tutumu öne sürebiliriz. Bu yargıya göre, ülkemizde bir zekat kurumu tesis edilebilirse insanların zekat ibadetine olan teveccühü artar diyebiliriz kolaylıkla. Metnin amacı tam olarak bu anlayışı sorgulamaktır. Yapılan tartışmalar fıkıh ekseninde ilerlemeyecektir. Yoksa bir İslam devletinde zekatın merkezden toplanması konusunda bir şüphe yoktur (Selçuk ve Görmüş, 2019). Hz. Peygamber (s.a.v) döneminden itibaren zekat merkezden görevlendirilen yetkililer tarafından toplanmaktadır. Dolayısıyla zekata kurumsal bir kimlik kazandırma çabalarına pejoratif bir tutum takınmak ya da hiçe saymak, bu uygulamanın kaynağını da beraberinde sorgulamayı getirmektir. Böyle bir sorgulamaya girmek gibi bir gaye bulunmamaktadır. Buradaki amaç, insanların yapılan bu çalışmaları doğru bir yere konumlandırıp, sonuçlarını da doğru bir şekilde öngörmelerini sağlamaktır. Aksi takdirde yaşanılan hayal kırıklıkları ve istenilen sonuçlara ulaşılamamasının nedeni olarak uygulamanın kendisi görülebilir. Bu ise iyi bir niyetle yola çıkılmasına rağmen insanları yanlış bir menzile götürmektir ki önceki durumdan daha kötü bir konuma düşmek anlamına gelir.

\section{Zekatın Kurumsallaştırılmasının Nedenleri}

$\mathrm{Bu}$ bölümde merkezi bir zekat müessesi tesis etme çabalarının arkasında yatan nedenler ekonomik, siyasi, sosyal ve din bağlamında incelenecektir ve tartışlacaktır. Ülkemiz için önerilen modelleri analiz etmeden önce bu resmin doğru bir şekilde ortaya konması, böyle bir müessesenin ne amaçla kurulup, sonuçlarının da neye göre değerlendirilmesi gerektiğinin tespiti açısından önem arz etmektedir. Meseleyi mümkün mertebe geniş bir şekilde incelemek için böyle bir tasnife gidilmiştir. Var olan uygulamalarda belli alt başlıkların öne çıktığ görülmekle birlikte, bir bütün olarak da geçerli olabilmektedirler. 


\subsection{Ekonomik Nedenler}

Konunun iktisadi yönü ele alındığında ilk akla gelecek şey, zekatın kurumsallaşmasıyla birlikte toplanılan miktarın da artacağına yönelik iddia olacaktır. Fakat bu iddianın test edilebilmesi için öncelikle elimizde zekatın merkezi bir kurum tarafından toplanmadan önce ne miktarda dağıtıldığına dair bir veri bulunması gerekmektedir. TÜSEV tarafından yayınlanan "Türkiye'de Bireysel Bağışçılık ve Hayırseverlik" adlı raporda, insanların zekat verip vermediklerine ve bağışlarını ne ölçüde kurumlar aracılığıyla gerçekleştirdiğine dair saha çalışması sonuçları yer almaktadır (Çarkoğlu ve Aytaç, 2016). Ancak yukarda bahsettiğimiz karşılaştırmayı yapmak için yeterli çalışmalar yoktur. Bu noktada unutulmaması gereken şey şudur ki, hayır faaliyetlerinde veri toplamak ve veriye ulaşmak çok zordur (May, 2013). Sorunun çözümü için yapılan şeylerden biri ülkelerin zekat potansiyellerini hesaplayarak, böyle bir miktarın ekonomiye enjekte edildiğinde ortaya çıkaracağı sonuçlarla ilgili projeksiyonlar yapmak ve halihazırdaki durumu elde edilen sonuçlarla kıyaslamak olmuştur (Turan, 2018). Lakin bunun sağlıklı bir yöntem olduğunu söylemek oldukça güçtür. Özellikle hayvancılık ve tarım sektöründeki değişken oranlı zekatı doğru bir şekilde hesaplayabilmek ülke bazında mümkün değildir. Banka mevduatlarından yola çıkılarak yapılacak bir hesap ise kişilerin bilgilerine tam manasıyla haiz olunmadığ için kesin bir sonuç ortaya çıkaramayacaktır. Örneğin, bir kişinin banka hesabında o an için nisap miktarının üstünde bir meblağ bulunabilir ama bu kişinin sahip olduğu borcu onun zekat mükellefi olmasını engelleyebilir. Verilen örneğe, o kişinin borçlu olduğu kişinin de zekat vermekle yükümlü olduğu ve dolayısıyla bu miktarın alacaklının zekat nisabına dahil edilebileceği şeklinde bir itiraz getirilebilir. Küreselleşmenin bu kadar yaygın olduğu günümüzde bu durumun her zaman geçerli olmayacağı açıtır. Dolayısıyla böyle bir hesaplama bize kesin bir sonuç vermekte yetersiz kalacaktır.

Diğer bir mesele ise atıl konumdaki varlıkların zekat sayesinde ekonomiye kazandırılmasıdır. Kurulacak müessese sayesinde bu süreç daha etkin bir şekilde yönetilebilecektir (Selçuk ve Görmüş, 2019). Sermayenin dağıtılması her ne kadar cari ekonomik düzen için ilk bakışta hoş karşılanmasa bile sonrasında olumlu etkileri olacağı muhakkaktır. Daha çok toplamak için önce dağıtmak gerekebilir. Fakat bu konuyu değerlendirirken başka bir yöne dikkat çekmek gerekmektedir. Aslında burada verimliliği sağlayan şey kayıt dışı oluşabilecek ekonomileri kayıt altına almakla olmaktadır. Yani insanların yastık altlarında tuttukları varlıkları, devletten gizledikleri ticari malları veya toprakları merkezi zekat kurumu sayesinde finansal sistemin içine girecektir. Bu durum ise özellikle vergi konusunda devletten korunmaya çalışan insanları başka bir noktada açığa düşüreceğinden dolayı insanların zekat kurumuna olan rağbetini düşürecektir. Bunun örneğini zekatın Malezya'da ilk olarak kurumsallaştığ dönemde görmekteyiz. Uygulamaya öşür ile başlanmış ve insanlardan tarlalarını ve hasatlarını amillere beyan etmeleri istenmiştir. Fakat çoğu kişi bunu reddetmiştir. Reddetmeyen kişiler arasında ise tarlasının ölçüsünü ve hasadının miktarını az olarak beyan edenler olmuştur (May, 2013). Zekat için ayrılan atıl fonların merkezi bir kurum tarafından toplanmasının, sosyal harcamalar noktasında devlet bütçesini de rahatlatacağını ve daha iyi 
planlama yapılabileceğini söyleyenler de olmuştur (akt. Selçuk ve Görmüş, 2019). Fakat burada da ne kadar toplanılacağı meçhul olan bir miktar üzerinden planlama söz konusu olacaktır. Dolayısıyla bütçe için daha büyük sorunlar ortaya çıkarması olasıdır.

\subsection{Siyasi Nedenler}

Devletin müdahil edilmek istendiği bir alanın politik yönünü ihmal etmek konunun eksik anlaşılmasına neden olacaktır. Ayrıca İslam iktisadına politik ekonomi düzleminde yaklaşma eğilimi bu noktada işimize yarayacaktır (Asutay, 2007). İslam coğrafyasındaki siyasi otoritelerin zekat toplama işini devlet eliyle gerçekleştirmek istemeleri ilk olarak meşruiyetlerinin sorgulanmasına neden olmuşlardır. İnsanlar, ulus devletin böyle bir hakkı olup olmadığına dair şüpheye düşmüşlerdir. Hatta Malezya'da ilk başlarda halk arasında devletin topladığı ve insanların kendi dağıttıkları zekatlara farklı isimler verilmiştir. İlkinin ismi zakat raja yani devlet zekatı, ikincisinin ismi ise zakat peribadi yani hakiki zekattır. İnsanlar, meşru olarak görmedikleri yönetimlerine zekatlarını vermek istememişlerdir (May, 2013). Aynı durum Filistin'de de yaşanmış, Batı Şeria yönetimi zekat paralarını toplamak istediğinde gerek kendi ülkelerinde gerekse de dişardan gelen miktarlarda ciddi bir düşüş yaşanmıştır. Ayrıca devletin toplanan paraları nerede tutacağı, nasıl dağıtacağı soruları da insanların zihinlerini meşgul etmiştir. Pakistan'da toplanan paraların vadeli hesaplarda tutulması ve dağıtılan kişilerin şüpheli olması insanların buraya teveccühünü azaltmıştır (May, 2013). Bu tepkileri anlamak için insanların modern ulus-devlete karşı tepkisini bilmemiz gerekmektedir. Otoritelere tam manasıyla güven duyulmadığı için insanlar kendilerine alanlar oluşturmaya çalıştırmışlardır. Bunun da finansmanını zekat gibi hayır paraları sayesinde sağlayabilmişlerdir. Hayır faaliyetleri kişisel çabalar üzerinden moderniteye karşı sosyal ve ekonomik bir direnç noktası oluşturmuştur (Hart, 2007). Yani zekatla birlikte ortaya çıkan kayıt dışı ekonomi, modern ulus devletten bağımsız bir politik alan oluşmasını sağlamıştır. Bu alanı dağıtmak ise devletin ortaya koyacağı bir zekat toplama sistemiyle mümkün olacaktır. Keza Misır özelinde bunun örneğini görmek mümkün olacaktır. Mısır yönetimi, devlet kontrolünde olmayan camilerin zekat gelirlerini engellemek istemesinden dolayı kendi kontrollerindeki camilerde zekat toplamaya başlamıştı. 80'li yıllarda alınan bu kararlar halk arasında ilgi görmemiş, insanlar zekatlarını tekrar diğer camilere vermeye veya kendi imkanlarıyla dağıtmaya başlamışlardır (May, 2013). Endonezya'da ise hem devletin hem de sivil toplum kuruluşlarının zekat kurumları mevcuttur. Fakat bu kurumlar da ülkenin zekat potansiyelinin önemli bir kısmını toplamakta başarısız olmuşlardır. Tahmin edilen toplam zekat miktarı 19,3 trilyon Endonezya rupisi iken toplanılan tutar 1,5 trilyon Endonezya rupisi olmuştur. Bu miktarı artırmaya yönelik önlem ise devletin kendi zekat kurumunu tek yasal zekat toplama otoritesi ilan etmesidir. Zekat konusunda insanların devlete olan güvensizlikleri, onları yerel organizasyonlara yönlendirmiştir (Halimatusa'diyah, 2015). 


\subsection{Sosyal Nedenler}

Giriş kısmında da belirtildiği üzere zekatın sosyal düzeyde çok önemli etkileri ortaya çıkmaktadır. Özellikle sosyal adaletin sağlanması noktasında zekat, Müslüman toplumlar içinde çok önemli roller oynamaktadır. Kurumsallaşmıs bir yapıya sahip olması zekatın düzenleyici yanının daha iyi ortaya çıkmasını sağlayabilir düşüncesi, alanla ilgilenen araştırmacılar arasında yaygındır. Fakirliğin azaltılması yönünde zekatın etkisiyle ilgili çalışmalar sıklıkla yapılmaktadır (Ali ve Hatta, 2014; Halimatusa'diyah, 2015; Muhammad, Ali ve ImranAbdullah, 2013; Sarif, 2013; Sohag, Mahmud, Alam ve Samargandi, 2015). Fakat kurumsallaşmış zekatın etkilerinin tam olarak ortaya konması zor olmaktadır. Şunu unutmamak gerekir ki halihazırda zekatlarını ödeyen insanlar bulunmakta ve merkezi kuruma da ödemeyi yapacak insanlar genellikle bu grup içerisinden olacaktır. Zekatın bölgesel fakirliği ortadan kaldırma noktasında etkili olup olamayacağına dair Bangladeş özelinde yapılan bir çalışmada, organize edilmiş bir zekat dağıtımının insanların hayatlarına olumlu etkileri olduğunun gözlendiği fakat tam manasıyla yoksulluğu bitiremediği belirtilmiştir. Halbuki bu araştırmanın yapılma amacı, mikrofinans uygulamalarının fakirliği ortadan kaldırmada başarısız olduğu düşüncesinden yola çıkarak bu sorunun zekatla çözülebileceğini ortaya koymaktı. Bu düşüncenin arka planında yatan şey ise, inanç sistemlerinin ve kalkınma uygulamalarının birbirleriyle çelişen şeyler değil, bütünleşebilen bir yapıya sahip oldukları kanaatidir (Sohag ve diğerleri, 2015).

Zekatın sosyal etkilerinden birisi de zengin ve yoksul kimseler arasında bir köprü kurarak, alt gelir grubundaki insanların kendilerini toplumdan dışlanmış hissine kapılmasını engellemesidir (Selçuk ve Görmüş, 2019). Varlıklı kimseler zekatlarını vererek mallarını temizlemiş olmakta, aynı zamanda toplumdaki yoksulluk da azalmaktadır. Bu döngüyle birlikte bereketin hasıl olduğu görülecektir (Ali ve Hatta, 2014). Fakat kurumsallaşmış zekat uygulamalarının da eksik kalacağı yönler olacaktır. Zekat veren ve alan arasındaki karşılaşmayı önlemekle birlikte toplumda iyice zayıflamaya başlayan sosyal ilişkilere zarar verme ihtimaline sahiptir. Günümüzde yaygınlaşan toplu konut siteleri halihazırda değişik gelir gruplarında bulunan insanların var olan temas noktalarını ortadan kaldırıyorken, insanların hayır faaliyetleri için bir araya gelme gereksinimi de bu kurumun ortadan kaldırması mümkündür. Bu noktada şöyle bir itiraz getirilebilir; insanlar zaten yardımlarını belirli dernekler, vakıflar üzerinden gerçekleştiriyor ve bizzat bu faaliyetlerin içinde yer almıyorlar. Fakat söz konusu zekat olduğunda insanların meseleye daha hassas davrandıklarını varsayabiliriz çünkü bu farz olan bir ibadettir. İnsanlar kendi dağıttıkları zekatlarını özellikle yakın çevrelerine ve akrabalarına vermeyi tercih etmektedirler veya güvendikleri insanlara muhtaç kişilere ulaştırması için teslim ederler. Bu durum aynı zamanda toplumun bağlarını güçlendirir ve dayanışmanın tesisini kolaylaştırır. Ayrıca sivil toplum faaliyetlerinin bazıları zekat yoluyla finanse edilmektedir ve devletin bu alana dahil olması sivil alanın zarar görmesine neden olabilir. Bununla ilgili sıkıntılar Pakistan'da yaşanmıştır. İlk olarak Ziya-ül Hak tarafından başlatılan zorunlu zekat toplama uygulaması, medrese ulemasını endişelendirmiştir çünkü bu medreseler, büyük ölçüde topladıkları zekat 
ve bağış paralarıyla hizmet vermekteydiler. Merkeze gidecek zekat paralarının ne derece geri döneceği bir soru işaretiydi. Ayrıca, toplumla medresenin arasındaki bağlar da bu uygulamayla zayıflama ihtimaline sahipti. Bu nedenle uygulamaya karşı çıkılmıştır (May, 2013).

\subsection{Dini Nedenler}

Her ne kadar başka yönleri ön plana çıkartılırsa çıkartılsın, nihayetinde zekat bir ibadettir. Dini yaşama noktasında hassas davranmaya çalışan insanların ibadetlerini de en uygun şekilde yerine getirmek istemeleri gayet doğaldır. Zekat Hz. Peygamber (s.a.v) tarafından bizzat veya görevlileri vasıtasıyla toplandığından ve uzun bir süre de insanlar tarafından otoriteye verilerek icra edildiğinden günümüzde de bu şekilde yerine getirilmek istenmektedir. Hz. Osman döneminden itibaren toplama usulü değişmiş olsa bile Osmanlı dönemi de dahil merkezi bir zekat toplama uygulamasını tarihte görmüş bulunuyoruz (Selçuk ve Görmüş, 2019). Fakat bu konuyla alakalı modern dönemde bazı ihtilaflar ortaya çıkmıştır. Bir grup zekatın devlet tarafından toplanması gerektiğini düşünürken, bir grup modern ulusdevletlerin zekat toplayamayacağını iddia etmişlerdir. Aslında bu tartışmanın izdüşümlerini Müslüman toplumların geçmişte bazı dönemler başlarına geçen zalim yöneticiler zamanında görmekteyiz. Ulema bu konuyu tartışmış ve mezhepler arası bazı görüş ayrılıkları ortaya çıkmıştır. Bu konuda Şafii ve Hanefi mezhepleri ayrı düşmüşlerdir. Hanefilere göre kişi, zekatını görevliye teslim ettiğinde vazifesini yerine getirmiş olur. Bu konudaki bir diğer mesele ise Sünni idare altında yaşayan Şiilerin, kendi din anlayışları doğrultusunda Sünni bir yönetime zekat vermemek istemeleridir. Pakistan'da yaşayan Şiiler devlete zekat vermeyi reddetmiş ve bu konuda ciddi bir direniş göstermişlerdir. Eylemlerinin sonucunda zekattan muaf olma hakkını elde etmişlerdir. Fakat burada ilginç bir şey yaşanmış, devlete zekat vermek istemeyen insanlar Şii olmasalar bile kendilerini Şii olarak göstermişlerdir (May, 2013).

\section{Türkiye için Önerilen Modeller ve Değerlendirilmesi}

Ülkemizde aktif bir şekilde zekat toplayan dernek ve vakıflar mevcuttur. Fakat zekat için kurulmuş özel bir yapı bulunmamaktadır. Bu konuda bazı çalışmalar yapılmış ve öneriler geliştirilmiştir. Mervan Selçuk ve Şakir Görmüş (2019), “Zekatın Kurumsallaşması: Dünya Uygulamaları ve Türkiye için Model Önerisi” adlı kitaplarında konuyu geniş bir şekilde ele almışlar ve somut bir model geliştirmeye çalışmışlardır. Ali Özdemir (2013) ise zekat ve vergi meselesini tartıştığı makalesinde, ortaya çıkabilecek olası problemler için bazı öneriler ortaya koymuştur. Her ne kadar güncel bir tartışma olarak görünse bile, Salih Tuğ (1973) yıllar önce bu meseleye değinmiş, ülkemiz için gerekli olduğunu ve mevcut hukuki alt yapının buna imkan tanıdığından bahsetmiştir. Şimdi bu öneriler ele alınıp sorunlu yönleri ortaya koyulmaya çalışılacaktır.

Laik bir yönetim anlayışına sahip olan ülkemizde, cumhuriyetin ilk yıllarından itibaren din işleriyle resmi bir kurum olan Diyanet İşleri Başkanlığı ilgilenmiştir. Din işleri tabirinin kullanılmasına yapılacak herhangi bir itiraza karşı şu belirtilmelidir ki; makalenin muhtevası 
bu tartışmayı yapmaya müsait değildir. Dolayısıyla genel kullanıma uyularak böyle bir tercihte bulunulmuştur. Zekatın kurumsallaşması meselesi gündeme geldiğinde sahip olduğu hukuki zemin ve organizasyonel yapısı nedeniyle DİB'na aktif bir rol verildiğini görmekteyiz (Selçuk ve Görmüş, 2019; Tŭ̆, 1973). Selçuk ve Görmüş (2019) modellerinde, zekat kurumunu paydaşlar üzerinden tesis etmeyi önermişlerdir. Belirlenen paydaşlar ise DİB, katılım bankaları ve dernek ve vakıflardır. Modele göre DİB içerisinde kurulacak olan Zekat ve Hayır İşleri Genel Müdürlüğü kurum adına bu vazifeyi üstlenecek birim olacaktır. Bu genel müdürlüğe bağlı olarak üç daire başkanlığı önerilmiştir. Bunların ilki Zekatın Hesaplanması Daire Başkanlığı'dır. Görevi ise ülke genelinde zekata konu olan malların ve düşen zekat miktarlarının usulünce tespitidir. İkincisi ise Zekat Konusunda Farkındalık ve Bilinçlendirme Daire Başkanlığı'dır. Bu birim ise zekat ibadetinin bilinirliğinin artırılması yönünde çalışmalar yapacaktır. Kamuoyunda yaygın halde bulunan yanlış bilgilerin düzeltilip, olumsuz algıların değiştirilmesi için yapılacak faaliyetler de bu birimin sorumluluğunda olacaktır. Son olarak ise Zekat Eğitimi Daire Başkanlığı gerek kurum içi, gerekse vatandaşların zekatla ilgili gerekli donanımları edinmesi yönünde çalışmalar yapacaktır. Tuğ (1973), DİB’nın sahip olduğu personel ve imkanlarıyla zekatın kurumsallaşmasında başarılı olacağını iddia etmiştir. Ayrıca sahip olduğu hukuki statünün gerekli zemini oluşturduğunu belirtmiştir. Laik bir yönetim altında bulunulsa bile böyle bir organizasyonun zorunlu olduğu savunulmuştur. Bu çalışmadan yaklaşık yedi yıl sonra, Bursa şehrinde yerel dinamikler tarafından müstakil bir zekat vakfı kurulmuştur. Fakat bir yıl sonra, askeri yönetim tarafından laikliğe aykırı bulunup kapatılması yönünde karar alınmıştır (akt. Selçuk ve Görmüş, 2019). Organizasyon yapısına kavuşacak zekatın katkısı olarak, toplanılan fonların DİB'nın bağımsız bir yapıya kavuşmasını sağlayacak maddi olanağı sunacağı ve bu sayede sorumluluğundaki hizmetleri daha iyi bir şekilde yerine getirebileceği belirtilmiştir. Bununla birlikte uluslararası düzeyde de kurumun saygınlığının ve itibarının artacağı vurgulanmıştır (Tuğ, 1973). Bağımsız bir DİB için zekat müessesi tesis etmesini devletten beklemek abes olacaktır. Bağımsız olmaması için devlet kontrolüne alınan bir kurumun, aynı devlet aklı tarafından muhtar hale getirilmesini beklemek tutarlı gözükmemektedir.

Yukarda bahsettiğimiz önerilerin Türkiye'de başarılı olmayacağı iddia edilebilir çünkü değinilmesi gereken önemli bir sosyal faktör göz ardı edilmektedir. Bu da ülkemizde var olan tekilci ahlak kültürüdür. Kollektif bir yapıya sahip olan toplumumuz, kollektifliğini tekilcilik üzerinden gerçekleştirmektedir. Kişilerin sahip olduğu toplum algısı, ülkede yaşayan insanların tek tek bir araya gelerek oluşturdukları yapıyı aşan bir şekildedir. Yani, bir metatoplum anlayışına sahip olduğumuzu söyleyebiliriz. İşte bu göremediğimiz veya dokunamadığımız meta-toplum, birey karşısında normatif bir üstünlüğe sahiptir. Dolayısıyla benlikler ortaya çıkarken verili sosyal ilişkiler etkili olmaktadır. Bunun sonucunda ise ortaya bağlamsal ahlak ortaya çıkmaktadır. Bağlamsal ahlak içinse net bir sınır çizmek mümkün değildir. Kişinin sahip olduğu sosyal çevrelerin kendi içerisindeki sınıflandırılmasına göre değişik ahlak yapıları ortaya çıkabilir (Önderman, 2007). Mesela tuttuğu takım, sahip olduğu siyasi görüş veya memleketi üzerinden bağlamsal ahlaklar geliştirip her birisine de farklı 
değerler verebilir. Bu durumun konumuzla olan alakası ise tesis edilecek merkezi kurumun insanımız için ne anlam ifade edeceğidir. Devlet kurumu olsa bile genel olarak kurumların güvenilirliği bağlamsal ahlak içerisinde değerlendirilebilir. DİB uzunca bir süre tartışma konusu olarak ülkede varlığını sürdürmüşken, son yıllarda yaşanılan siyasi dönüşümle birlikte geçmişte bu kuruma karşı çıkanlar tarafından sahiplenilmiş, geçmişte bu kurumu savunanlar tarafından ise sorgulanmaya başlanmıştır. Yani, DİB gibi bir kurum bile kendi güvenilirliğini inşa edememiş, değişen iktidarlar veya yöneticilere göre bağlamsal ahlak devreye girmiştir. Kurulacak merkezi bir zekat toplama kurumu da insanlar tarafından yine bu şekilde konumlandırılacaktır. Bağlamsal ahlakın getirdiği gönül rahatlı̆̆ıyla, isteyerek zekatlarını bu kuruma verecek kişilerin aynı davranışı olası bir değişimde sürdürecekleri soru işaretidir. Aynı şekilde böyle bir kurumu ciddi şekilde itham edecek insanlar da sonrasında bu kurumun bağışçıları arasına katılabilirler. Kurumun bir tüzel kişiliği olacağı veya aynı kurallarla yönetileceği çoğu kimse için bir anlam ifade etmeyecektir.

Bir diğer mesele ise ülkemiz gibi laik bir hukuka sahip ülkede zekat ve vergi ikileminin nasıl çözüleceğidir. Bu konuda yapılan bir çalışmada (Özdemir, 2013), devletin zekat toplayacağı bir yapı oluşturarak, isteyen vatandaşların zekatlarını buraya yatırdıktan sonra gelir vergisinden düşülmesi sağlanabilir denmektedir. Açıkçası bu öneri mevcut hukuki alt yapıyla çözümü zor bir meseledir. İtiraz olarak halihazırda bazı kurum ve kuruluşlara yapılan yardımların vergiden muaf tutulması dile getirilebilir (Özdemir, 2013; Selçuk ve Görmüş, 2019). Hangi yardımların bu kapsamda değerlendirileceği yürütme tarafından alınan kararla belirlenmektedir. Dolayısıyla zekat gibi İslam'ın emri olan bir şeyin laik bir devlet tarafından, üstelik kendi gelirinden feragat etmek suretiyle bu şekilde kabul edilmesi beklenemez. Özdemir (2013), bu önerisi sayesinde çeşitli nedenlerden ötürü devlete vergi vermekten kaçınanların, devlete zekatlarını teslim edeceğini iddia etmektedir. Bu sayede devletin gelirleri artacak, yaptığı sosyal harcamaları diğer bütçe kalemlerine aktararak sosyal harcamaları zekat fonundan karşılayabileceği belirtilmiştir. Buna benzer bir uygulama Pakistan'da yapılmıştır. Maliye daireleri zekat pulu çıkarmış ve ülke genelinde satışa sunmuştur ancak insanlar tarafından rağbet görmemiştir. Ayrıca zekatlarını bu fona yatıran kişilere, yatırdıkları miktarı talep ettikleri kişilere dağıtılması için tercih hakkı sunulabileceği önerilmiştir. Bu sayede toplanılan miktarın da artacağı düşünülmektedir. Vergi kaçırma ve vergiden kaçınma davranışlarının ne derece yaygın olduğunun farkında olunmasına rağmen (Özdemir, 2013), bu önerinin ülkemizde işe yarayacağını düşünmek fazla naif bir tutum olsa gerektir. Yaşanılması kuvvetle muhtemel olumsuzlukların nasıl önleneceği, hangi hukuki yaptırımların bu durumu engelleyeceği veya cezalandıracağı düşünülmemiştir. Zekatın sıhhat şartlarından biri olan temlik gerçekleştikten sonra, o kişinin kendi rızasıyla kendisine zekat gönderen kişiye parasını vermesine kim, hangi hakla engel olacaktır? Dolayısıyla bu öneri teorik düzeyde çok güzel gözükse de, pratikte uygulanabilirliğine ilişkin kültürel zeminin buna imkan vermeyeceği yukarıda bağlamsal ahlak üzerinden dile getirilmiştir. Ayrıca devletin vergi gelirlerinin de kurulacak zekat fonu sayesinde artmayacağını tahmin etmek çok zor olmayacaktır. 


\section{Sonuç}

Zekatın kurumsal hale getirilmek istenmesinin temel gerekçesi olarak daha çok miktarı bir arada toplayıp, etkili bir şekilde kullanmak olduğu söylenebilir. Fakat Türkiye'de istenilen hedefe ulaşılması pek mümkün gözükmemektedir çünkü toplanan zekat miktarının artmasının önüne geçebilecek bir mesele bulunmaktadır. Zekatın armağan kültürünün mündemiç olduğu toplumlarda, bu ilişkilerin varlığını sürdürmesinde önemli bir rolü bulunduğu iddia edebilir. Zenginler, yıllık olarak mallarından bir kısmını verip temizleme ihtiyacı duyarlar. Burada doğrudan bir "lanetli pay" kıyası yapmamaktayım (Bataille, 2010). Fakat zekat veren kişinin bunu bir armağan ilişkisine dönüştürüp üstünlük kurması çok kolay bir şeydir. Bundan ötürü böyle bir tahakkümün kurulmasını engellemeye yönelik ciddi uyarılar mevcuttur. Zekat verecek kişi, bu eylemini karşılıksızlık üzerine inşa etmesi gerektiğinin farkında olması gerekir. Günümüzde bu duruma ne kadar dikkat edildiğini kestirmek kolay bir iş değildir. Yüklü miktarda mükellefiyetleri bulunan kişiler, bu miktarı dağıtmak üzere verdikleri vakıf, dernek gibi sivil toplum kuruluşlarının oluşturmuş olduğu sosyal çevrelerde de belli bir itibar görmek isteyebilirler. Veyahut yüklü bir bağış almak isteyen bu tarz kuruluşlar, bu kişilerle bir armağan ilişkisinin gerektirdiği şekilde ilişkiler kurabilmektedirler. Dolayısıyla merkezi bir kurum tarafından zekatın toplanması söz konusu olduğunda, bu tür ilişkilerini sürdürmek isteyen kişiler böyle bir kuruma zekatlarını vermekte tereddüt edip kolaylıkla reddedebilirler. Hareket alanlarını kaybetmek istemeyen sivil toplum örgütleri de irtibatta oldukları kişileri, merkezi kuruma zekatlarını vermekten uzak tutabilirler. Sonuçta buradaki armağan ilişkisinin çift yönlü olduğu unutulmamalıdır. Bir organizasyon ne ölçüde bağış alır, ne kadar maddi imkanlara sahip olursa, bunları dağıtarak da o ölçüde armağan ilişkisi tesis etmiş olur. Kapsamını ve yoğunluğunu artırma fırsatına kavuşmuş olur. Bu yapıyı bozma yönünde atılacak adımlar bir tepkiyle karşılaşabilir ya da böyle bir kurumun yönetimi için sivil toplum içerisinde bir mücadele gerçekleşebilir. Türkiye'de potlaç kültürünün hala önemli ölçüde varlığını koruduğunu unutarak atılacak adımlar başarısızlığa neden olabilecek sonuçlar doğurabilir (Akay, 1999). Komşudan gelen bir ikram tabağını geriye boş göndermeyecek şekilde günlük hayatımızı etkileyen bir olgu, bu konuda da fazlasiyla etkin olacaktır.

Başlarken ifade edildiği üzere bu makalenin amacı zekatın devlet eliyle toplanılmasına karşı çıkmak değildir. Amaç, istenilen şeyin tam olarak niçin istendiğini anlayabilmek ve sonuçlarını değerlendirirken adilane davranabilmektedir. Yani, kurumsal bir yap1 oluşturduktan sonra beklentileri karşılayamayan bir zekat müessesesi karşımıza çıktığında sorunu zekatta aranmasının önüne geçmektir. Modern ulus-devlet döneminde yaşayan Müslümanların sisteme ayak uydurmakta zorlanması gayet normaldir. Doğrularını bu düzen içinde yaşayabilmeleri oldukça zor olabilmektedir. Fakat bu durum eklektik çabalarla Müslümanların kendisi tarafından daha zor hale getirilmekte ve kendi değerlerinin sorgulanmasına yol açmaktadır. İslam toplumunun kurucu unsurları tarafından inşa edilmemiş bir toplumda yaşanıldığı unutulmamalıdır. İktisadi manada bir selefilik tuzağına düşmemek adına adımlarımızı bilinçli atmamız gerekmektedir (Kızılkaya, 2019). Ayrıca 
devlet eliyle ya da zorlamayla gidilen uygulamaların gönüllü olan uygulamalardan daha başarısız olduğu unutulmamalıdır (Selçuk ve Görmüş, 2019). Sonuç olarak, zekatı kurumsal hale getirmeden önce alt yapısının iyi oluşturulduğundan emin olunmalı ve bu yönde gayret gösterilmelidir. 


\section{Kaynakça}

Akay, A. (1999). Armağan (1. bs.). İstanbul: Bağlam.

Ali, I. ve Hatta, Z. A. (2014). Zakat as a poverty reduction mechanism among the muslim community: Case study of Bangladesh, Malaysia, and Indonesia. Asian Social Work and Policy Review, 8(1), 59-70. doi:10.1111/aswp.12025

Asutay, M. (2007). A Political Economy Approach to Islamic Economics: Systemic Understanding for an Alternative Economic System. Kyoto Bulletin of Islamic Area Studies, $1(2), 3-18$.

Bataille, G. (2010). Lanetli Pay (1. bs.). Ankara: Dost.

Çarkoğlu, A. ve Aytaç, S. E. (2016). Türkiye'de Bireysel Bağıış̧ılık ve Hayırseverlik. İstanbul.

Gümüş, N., Yardımcıoğlu, F. ve Altıntaş, N. (2019). the Role of Zakat Potential in Reducing Poverty in Turkey. International Journal of Islamic Economics and Finance Studies, 5(2), 90110. doi:10.25272/ijisef.575488

Halimatusa'diyah, I. (2015). Zakat and Social Protection: The Relationship Between Socioreligious CSOs and the Government in Indonesia. Journal of Civil Society, 11(1), 79-99. doi:10.1080/17448689.2015.1019181

Hart, K. (2007). Performing Piety and Islamic Modernity in a Turkish Village. Ethnology, 46(4), 289-304.

Kızılkaya, N. (2019). İktisadi Selefilik: Modern İslam İktisadı Çalışmalarında Hafıza Kaybı. İslam İktisadı Metodolojisi Sorunlar ve Çözüm Önerileri içinde (1. bs., ss. 401-430). İstanbul: İktisat.

May, S. (2013). Political Piety: The Politicization of Zakat. Middle East Critique, 22(2), 149-164. doi:10.1080/19436149.2013.783536

Muhammad, N., Ali, S. R. ve ImranAbdullah. (2013). The Role of Zakat in Improving the Economic Status of Beneficiaries in Khyber Pakhtunkhwa. Journal Managerial and Sciences, 7(2), 243-253.

Önderman, M. (2007). Türkiye'de Devlet, Sosyal Kontrol ve Öznellik. İstanbul: Filiz Kitabevi.

Özdemir, A. (2013). Zekât ve vergï mükellefïyetïnde firsat eşitlï̆ї ve adaletïn sağlanmasi. EKEV Akademi Dergisi, 56(Yaz).

Sarif, S. (2013). Income Generation Through Zakat: The Ialamization Impact on Malaysian Religious Institution, 358.

Selçuk, M. ve Görmüş, Ş. (2019). Zekatın Kurumsallaşması Dünya Uygulamaları ve Türkiye için Model Önerisi (1. bs.). İstanbul: İktisat. 
Sohag, K., Mahmud, K. T., Alam, F. ve Samargandi, N. (2015). Can Zakat System Alleviate Rural Poverty in Bangladesh? A Propensity Score Matching Approach. Journal of Poverty, 19(3), 261-277. doi:10.1080/10875549.2014.999974

Tuğ, S. (1973). Zekat'ın Yeniden Merkezileştirilmesi. İslam Medeniyeti, 3(28).

Turan, M. (2018). Zekat Politikası Ekonomi-Politik Yaklaşım (1. bs.). İstanbul: Mevsimler Kitap. 


\section{Extended Abstract}

Zakat is one of the first solutions that come to mind at the point of providing social justice for Muslims who are looking for an alternative model to the current economic system. One of the most important topic of this popular issue is the institutionalization of zakat by the state. Since the time of the Prophet (p.b.u.h), zakat has been collected by the officials assigned from the center. Therefore, to adopt a pejorative attitude to corporate identity of zakat, or to ignore it, will bring together to query the source of this practice. Our aim here is to ensure that people consider these studies accurately and predict their results. Behind this phenomenon, not only religious reasons are shown as basis, but other dimensions of the issue are tried to be revealed. In the study, these reasons were evaluated under four main categories; economically, politically, socially and religiously.

Considering the economic aspect of the issue, the first subject will be the claim that the amount collected will increase with the institutionalization of zakat. However, in order to be able to approve this claim, we first need to have a data on how much amount of zakat was distributed before it was collected by a central institution. One of the things done for the solution of the problem is to calculate the zakat potentials of the countries and make projections about the results that such an amount would get when injected into the economy and compare the current situation with the results obtained. However, it is very difficult to say that this is a healthy method. It is not possible to accurately calculate the variable rate of zakat, especially in the livestock and agriculture sectors. Another issue is to bring the idle assets to the economy thanks to zakat. Here, efficiency is achieved by registering economic activities that may occur informally. This will reduce people's interest in the zakat institution, as it will expose people who are trying to avoid taxes.

Neglecting the political aspect of an area in which the state is intended to be involved will lead to an misunderstanding of the issue. The fact that the political authorities in the Islamic geography wanted to carry out the zakat collection by the state caused the question of their legitimacy. People have doubted whether the nation state has such a right. To understand these responses, we need to know how people react to the modern nation-state. Since the authorities were not fully trusted, people have tried to create spaces for themselves. They were able to finance this with charitable money like zakat.

Zakat plays very important roles in Muslim societies to ensure social justice. One of the social effects of zakat is that it builds a bridge between rich and poor people and prevents people in the lower income group from feeling excluded from society. Wealthy people have been cleaning their property by giving their zakat, and at the same time, poverty in society is decreasing. With this cycle, it will be seen that abundance is the result. But institutionalized zakat practices can have weaknesses. While preventing the confrontation between zakat giver and receiver, it has the possibility of harming social relations which are getting weaker in the society. 
Although zakat has other aspects, it is ultimately a worship. It is quite natural that people who try to be sensitive about religious life want to perform their worship in the most appropriate way. Since the Prophet (p.b.u.h), zakat was gathered by himself or his officials and was given to the authorities for a long time, it is desired to be fulfilled in this way today. However, some controversies arose in the modern period regarding this issue. While some people thought that zakat should be collected by the state, some people claim that nation-states could not collect zakat.

There are associations and foundations that actively collect zakat in Turkey. But there is no special structure established for zakat. Some studies have been done on this subject and suggestions have been developed. Mervan Selçuk and Şakir Görmüş (2019) handled the issue extensively and tried to develop a concrete model. When it comes to the issue of institutionalization of zakat, we see that the Presidency of Religious Affairs has been given an active role due to its legal ground and organizational structure. In the model, they proposed to establish the zakat institution through stakeholders. The identified stakeholders are the Presidency of Religious Affairs, participation banks and foundations.

Turkish society, which has a collective structure, realizes its collectivity through singularism. The perception of society is in a way that transcends the cluster of people living in society. The meta-society, which cannot be seen and touched, has a normative advantage over the individual. As a result, contextual morality emerges. The relation of this situation with the subject is what the central zakat institution to be established will mean for Turkish people. Even if it is a state institution, the reliability of the institutions can be evaluated in contextual morality. While the Presidency of Religious Affairs continued to exist in the country as a subject of debate for a long time, with the political transformation experienced in recent years, it was owned by those who opposed this institution in the past and it was questioned by those who defended this institution in the past. In other words, even an institution such as the Presidency of Religious Affairs has not been able to build its own credibility.

Another issue is how to solve zakat and tax dilemma in a country with a secular law like Turkey. In a study on this subject (Özdemir, 2013), is said that by creating a structure where the state will collect zakat, it can be provided to deduct income tax from the citizens who want to give their zakat here. Obviously, this proposal is a difficult issue to solve with the existing legal infrastructure. Although writer is aware of tax avoidance behaviors, it should be naive to think that this proposal will work in our country. It is not thought that how to prevent possible problems and which legal sanctions will prevent or punish this situation.

The aim is to understand exactly what is desired and behave fairly while evaluating the results. In other words, when a zakat institution can not meet the expectation, the aim is to prevent finding problem in zakat. It can be quite difficult for Muslims living in the modern nationstate to experience their truth. However, this situation is made more difficult by Muslims by eclectic efforts. It leads to questioning their own values. It should not be forgotten that there is 
Türkiye'de Zekatın Kurumsallaşmasına Sosyo-Kültürel Bir Yaklaşım

a society that is not built by the founding elements of Islam. In order to avoid falling into a "Salafism" trap in the economic sense, we need to take our steps consciously. 